Endocrinol. Japon. 1987, 34 (1), 1-8

\title{
Demonstration of Calcium-Dependent Proteases (Calpains) and Thyroglobulin Proteolysis in Hog Thyroid Cytosol
}

\author{
Kazutaka HaRAgUCHI, Fumito AKASU, Toyoshi ENDO \\ AND TOSHIMASA ONAYA*
}

\begin{abstract}
The Third Department of Internal Medicine, University of Yamanashi Medical School, Tamaho, Yamanashi-ken 409-38, Japan
\end{abstract}

\begin{abstract}
$\mathrm{Ca}^{2+}$-dependent neutral proteases in hog thyroid cytosol were found to digest thyroglobulin. The protease activity was divided into two peaks by DEAE-cellulose column chromatography. Peak I was eluted at $0.2 \mathrm{M} \mathrm{NaCl}$ and required only a micromolar range of $\mathrm{Ca}^{2+}$ for its $50 \%$ activation, while peak II, which was eluted at about $0.4 \mathrm{M} \mathrm{NaCl}$, displayed little activity until the $\mathrm{Ca}^{2+}$ concentration was increased at more than $10^{-4} \mathrm{M}$. Among various inhibitors used, thiol protease inhibitors (leupeptin, E-64 and monoiodoacetic acid) were the most effective, whereas a calmodulin antagonist (trifluoperazine) and serine protease inhibitors (phenylmethyl-sulfony-fluoride and pepstatin A) were not effective, indicating that these $\mathrm{Ca}^{2+}$-dependent proteases corresponded to calpains 1 and 2. Among the substrates tested, casein was the best and thyroglobulin was also a good for calpain 2. By using immunoblotting procedure with anti-thyroglobulin antibody, it has been found that calpain 2 degrades thyroglobulin to yield $67 \mathrm{~K}$ and $46 \mathrm{~K}$ thyroglobulin and further that it also degrades $40 \mathrm{~K}$ thyroglobulin.
\end{abstract}

Evidence has been accumulating to indicate the ubiquitous distribution of $\mathrm{Ca}^{2+}$ dependent proteases (calpains) in a wide variety of tissues and cells (Mollgrem, 1980; DeMartino, 1981). There are two types of enzymes called calpain 1 and calpain 2 which are eluted in this order from a DEAE-cellulose column. The former has high and the latter has low $\mathrm{Ca}^{2+}$ sensitivities. Their physiological roles are diverse, but they are known to be closely linked to cellular $\mathrm{Ca}^{2+}$-related phenomena. It is known that filamin (Fox et al., 1983) and alpha-actinin (Reddy et al., 1975) are the

Received March 31, 1986 endogenous substrates of calpains and that they are closely linked to morphological changes and serotonin secretion in platelets. Calpains are also known to activate protein kinase $\mathrm{C}$ by rendering it into its phospholipid-independent form of M-kinase (Meyer et al., 1964).

Many investigations on thyroidal proteases dealt mainly with lysosomes. However, acidic $\mathrm{pH}$ optimum, defined existence in lysosomes and broad substrate specificity make it difficult for lysosomal enzymes to be involved in many physiological events occurring in cytosol.

It this study, we have demonstrated $\mathrm{Ca}^{2+}$-dependent proteases in hog thyroid. 


\section{Material and Method}

\begin{abstract}
Materials
Alpha-casein was obtained from E. Merk (Darmstadt, Hessen). Porcine thyroglobulin, ovalbumin, bovine hemoglobin, phenyl-methylsulfonyl-fluoride, pepstatin $\mathrm{A}$ and leupeptin were purchased from Sigma Chemical Co. (USA). DEAE-cellulose (DE-52) was obtained from Whatman Chemical Separation, Ltd. (USA). E-64 (N-(N-(L-3-trans-carboxyran-2-carbonyl)-L-leucyl) agmatine) was a generous gift from Dr. Masaharu Tamai, Taisho Pharmaceutical Co., Japan. Normal goat serum, goat anti-rabbit IgG and peroxidaseanti-peroxidase complex were obtained from Miles (USA). Goat anti-rabbit IgG-peroxidase conjugate was obtained from Kappel (USA).
\end{abstract}

\section{Preparation and assays of thyroidal calpains}

All subsequent procedures were carried out at $0-4^{\circ} \mathrm{C}$. Thyroid glands from $4-6$ pigs $(40 \mathrm{~g})$ were homogenized in 3 vol of homogenizing buffer (0.25 M sucrose, $10 \mathrm{mM}$ Tris- $\mathrm{HCl}(\mathrm{pH} 7.6)$, $5 \mathrm{mM}$ mercaptoethanol, $2 \mathrm{mM}$ EDTA) with a Waring blender at the top speed for $30 \mathrm{sec}$. Cytosolic fraction was obtained by centrifuging the homogenate at $105,000 \times \mathrm{g}$ for $90 \mathrm{~min}$. The cytosolic fraction was applied on a DEAEcellulose column $(1.4 \times 10.0 \mathrm{~cm})$ previously equilibrated with elution buffer $(0.1 \mathrm{M}$ sucrose, 10 $\mathrm{mM}$ Tris- $\mathrm{HCl}$ ( $\mathrm{pH}$ 7.5), $5 \mathrm{mM}$ mercaptoethanol and $1 \mathrm{mM}$ EGTA). After the column was washed with $300 \mathrm{ml}$ of the elution buffer, the elution was carried out with a linear gradient $(0-0.7 \mathrm{M})$ of $\mathrm{NaCl}$ in the same buffer.

Proteolytic activity was assayed with casein as the substrate by the method of Nishiura et al. (1978) with some modifications. The activity was determined using $200 \mu \mathrm{l}$ aliquots of each fraction of eluates from the DEAE-cellulose column in $50 \mathrm{mM}$ Tris- $\mathrm{HCl}$ buffer ( $\mathrm{pH} 7.6), 10$ $\mathrm{mM}$ 2-mercaptoethanol, $0.5 \mathrm{mM}$ EGTA and 20 $\mathrm{mM} \mathrm{KCl}$ (final volume $500 \mu \mathrm{l}$ ) with or without adding $\mathrm{Ca}^{2+}$. After incubation for $30 \mathrm{~min}$ at $37^{\circ} \mathrm{C}$, the reaction was stopped by adding $200 \mu \mathrm{l}$ of $20 \%$ trichloroacetic acid (TCA). The TCA soluble products formed were colorimetrically determined at $750 \mathrm{~nm}$ by the method of Lowry et al. (1951). One unit of the protease activity was defined as an increase in 1.0 absorbance unit at $750 \mathrm{~nm}$ in the presence of $\mathrm{Ca}^{2+}$ after subtraction of the result obtained in the absence of $\mathrm{Ca}^{2+}$.

\section{Free $\mathrm{Ca}^{2+}$ concentration}

The free $\mathrm{Ca}^{2+}$ concentration was adjusted by means of a metal-metal chelator buffer system using EGTA as the chelator. Composition of a metal-metal chelator buffer system was determined by calculation using the stability constant as described by Pershadsigh and McDonald (1980).

\section{Antiserum}

Antiserum to porcine thyroglobulin was made as follows: The emulsion of porcine thyroglobulin $(0.2 \mathrm{mg})$ and Freund's complete adjuvant $(0.2 \mathrm{ml})$ were injected at 6 sites in rabbit back and the same amount of antigen was boosted once a week. After 2 months, the rabbits were bled and the antiserum was tested by double immunodiffusion. The antiserum produced a precipitation line against porcine thyroglobulin.

SDS-polyacrylamide gel electrophoresis and immunoblotting

Aliquots of each fraction eluted from the DEAE-cellulose column were tested as the substrates of calpain 2 in place of casein. Incubations were for $30 \mathrm{~min}$ and stopped by treating the samples with $1 \%$ SDS and $2 \%$ mercaptoethanol for $5 \mathrm{~min}$ in boiling water. Samples were applied to SDS-polyacrylamide gel electrophoresis by the method of Laemmli (1970). The proteins and peptides in the gels were transferred to nitrocellulose membranes and then subjected to immunolabelling as described by Towbin et al. (1979) with some modifications: Nitrocellulose membranes were incubated with goat anti-rabbit IgG-peroxidase conjugate (1:200). Enzyme reaction was developed in $50 \mathrm{mM}$ Tris$\mathrm{HCl}$ buffer $(\mathrm{pH} 7.5)$ containing diaminobenzidine $(50 \mathrm{mg} / 100 \mathrm{ml})$ by adding $\mathrm{H}_{2} \mathrm{O}_{2}(0.05 \%)$.

\section{Results}

\section{Resolution of peak I and peak II calpain activities}

Protease assay was carried out either with or without adding $1 \mathrm{mM} \mathrm{CaCl}$ to the incubation medium. Fig. 1 shows the re- 


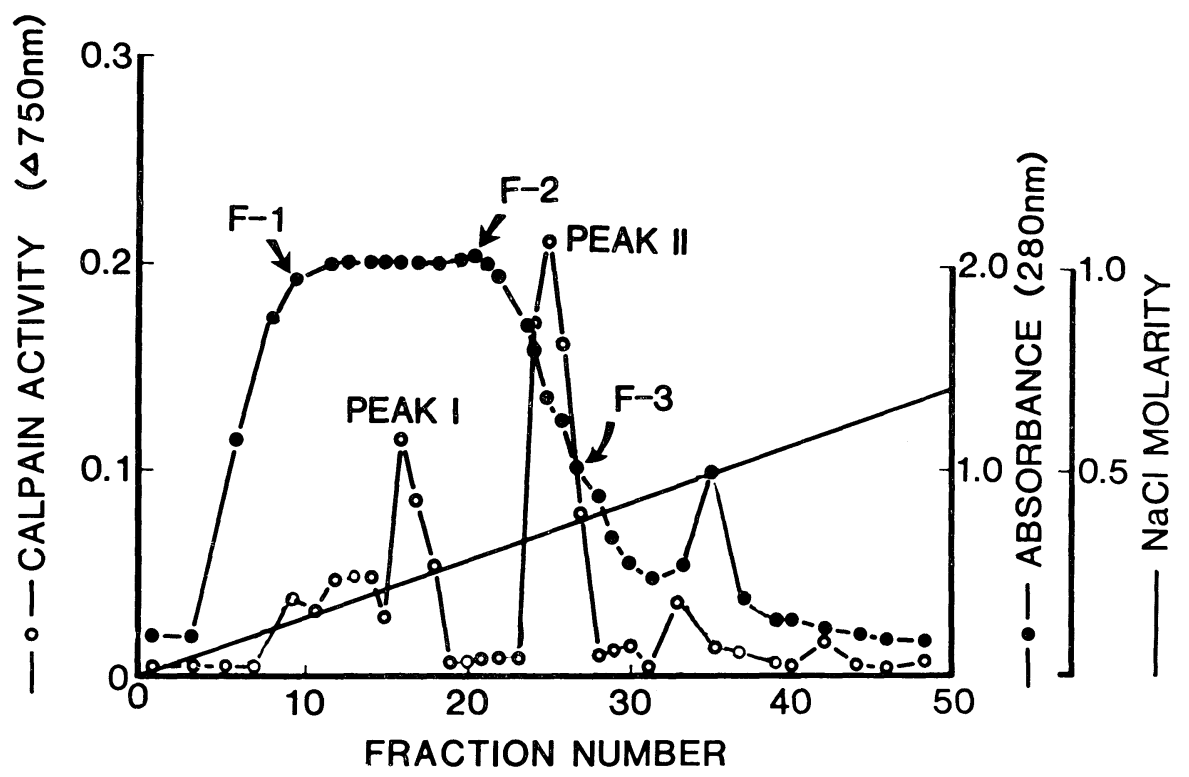

Fig. 1. Isolation of $\mathrm{Ca}^{2+}$-activated protease activity from hog thyroid cytosol. After washing the column with elution buffer, elution was carried out with a linear gradient of $\mathrm{NaCl}$ $(0-0.7 \mathrm{M})$ added to the buffer. Aliquots from the eluates were assayed for protease activity. Aliquots were also tested as the substrate of calpain 2 by using an immunoblotting procedure. Fractions 10, 20 and 26 were called F-1, F-2 and F-3, respectively, and used for the studies described in Fig. 5.

presentative chromatographic pattern of $\mathrm{Ca}^{2+}$-activated protease activity eluted on DEAE-cellulose column chromatography. An aliquot of each fraction was used for calpain assay. Two major peaks of protease activities were eluted. The first small peak was eluted at $0.2 \mathrm{M} \mathrm{NaCl}$ and the second peak was eluted at $0.4 \mathrm{M} \mathrm{NaCl}$. The calpain activities of peak I and peak II were $0.112 \mathrm{U}$ and $0.210 \mathrm{U}$, respectively.

\section{$\mathrm{Ca}^{2+}$ dependency}

Both peaks of protease activities were dependent on $\mathrm{Ca}^{2+}$, although there was a difference between the degrees of $\mathrm{Ca}^{2+}$ sensitivity of the two peaks. As shown in Fig. 2, the free $\mathrm{Ca}^{2+}$ concentration which maximally stimulated both protease activities was about $1.0 \mathrm{mM}$, but the $50 \%$ activation was obtained at $5 \mu \mathrm{M} \mathrm{Ca}^{2+}$ for peak I and $0.5 \mathrm{mM} \mathrm{Ca}^{2+}$ for peak II. At $3.0 \mathrm{mM} \mathrm{Ca}^{2+}$, both peak I and peak II activities were slightly suppressed by an unknown cause.

Peak I had rather little activity compared with peak II possibily because of coelution of an endogenous inhibitor (Inomata et al., 1983) (data not shown). Fractions 24, 25 and 26 (peak II) were collected and used mainly for further characterization of $\mathrm{Ca}^{2+}$ activated protease.

The enzyme was demonstrated to have a broad neutral pH optimum between 6.0 to 8.0 when assayed by caseinolysis (data not shown). In subsequent experiments, Tris-ECl buffer ( $\mathrm{pH}$ 7.5) was used.

Inactivation of calpain peak II by preincubation with $\mathrm{Ca}^{2+}$

Preincubation of peak II was started in the same assay mixture as used for calpains, but without casein. After this preincuba tion, casein was added to the medium and 


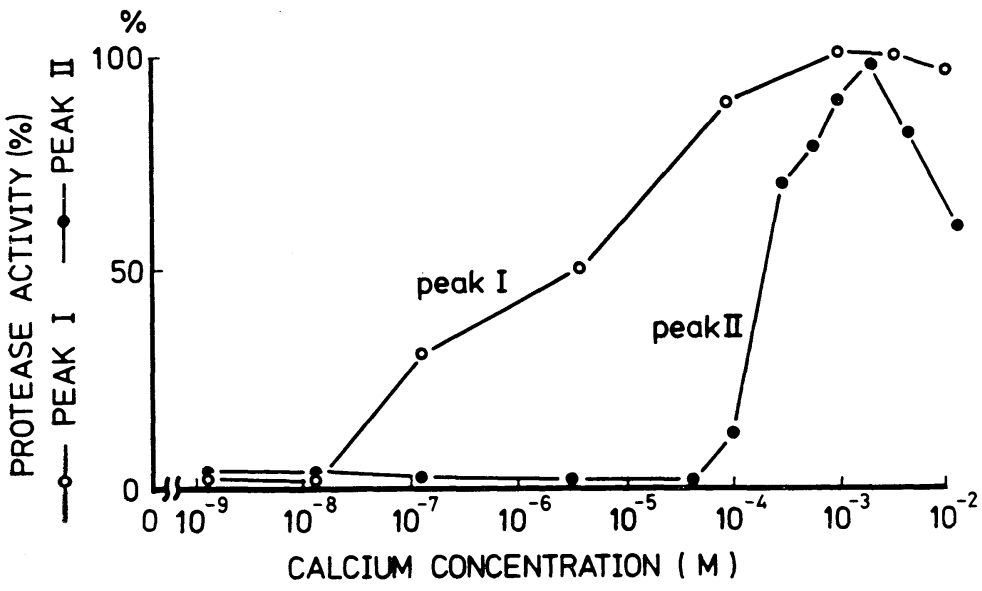

February 1987

Fig. 2. Effects of increasing $\mathrm{Ca}^{2+}$ concentrations on the activities of proteases from hog thyroid cytosol. $\mathrm{Ca}^{2+}$ concentrations were fixed by a EGTA-Ca ${ }^{2+}$ buffer method. Peak I and peak II activities were expressed as a percent of maximal activity measured in the presence of $1 \mathrm{mM} \mathrm{Ca}{ }^{2+}$.

the incubation was started.

After $3 \mathrm{~min}$, incubation was stopped by adding $200 \mu 1$ of $20 \%$ TCA. Peak II activity was decreased by $50 \%$ after preincubation with $1.0 \mathrm{mM} \mathrm{Ca}^{2+}$ for less than 2.5 min (Fig. 3). In contrast, peak II activity was fairly well maintained without $\mathrm{Ca}^{2+}$.

Enhancement of $\mathrm{Ca}^{2+}$ sensitivity of calpain peak II

To know the effect of preincubation with $\mathrm{Ca}^{2+}$ on $\mathrm{Ca}^{2+}$ sensitivity, peak II was preincubated with $1.0 \mathrm{mM} \mathrm{Ca}{ }^{2+}$ for $3 \mathrm{~min}$ and then dialyzed in the elution buffer at $4^{\circ} \mathrm{C}$. After dialyzing with the elution buffer for at least $5 \mathrm{~h}$, protease activity was mea-

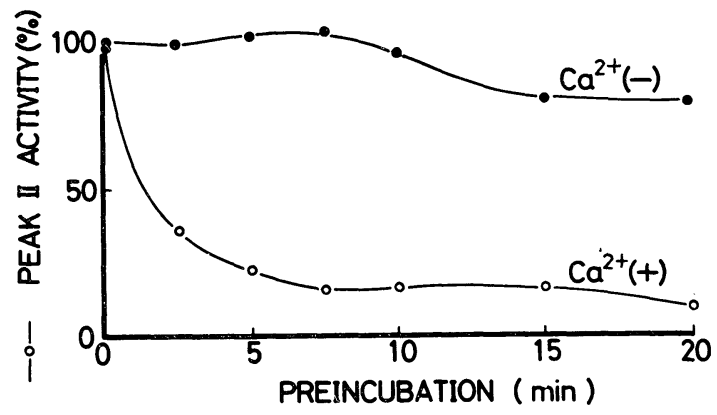

Fig. 3. Effect of preincubation of peak II with $\mathrm{Ca}^{2+}$. Preincubation was performed at $1.0 \mathrm{mM}$ $\mathrm{Ca}^{2+}$. After the preincubation, incubation was started by adding casein to the medium. The activities measured after each preincubation time was plotted.

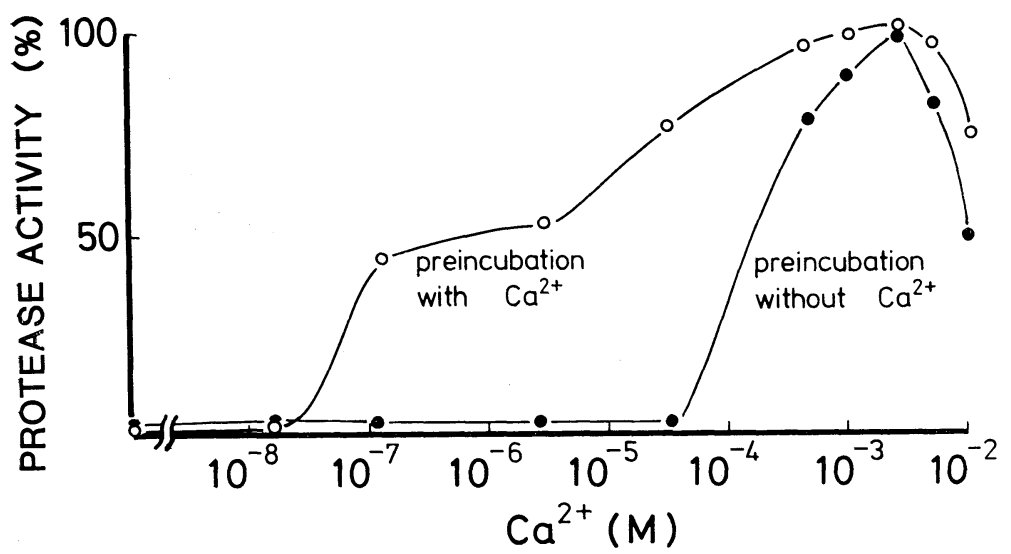

Fig. 4. Enhancement of $\mathrm{Ca}^{2+}$ sensitivitity of peak II. Preincubation was performed at $1.0 \mathrm{mM}$ $\mathrm{Ca}^{2+}$. After preincubation for 2 min, peak II was dialyzed against elution buffer for at least 5 h. Calpain activities of dialyzed samples were measured at various concentrations of $\mathrm{Ca}^{2+}$. 
Table 1. Effect of various protease inhibitors on protease activity

\begin{tabular}{lccc}
\hline \multirow{2}{*}{ Inhibitors } & & \multicolumn{2}{c}{ Remaining Activity (\%) } \\
\cline { 3 - 4 } None & & Calpain 1 & Calpain 2 \\
\hline Leupeptin & $5 \mu \mathrm{g} / \mathrm{ml}$ & 100 & 100 \\
& $20 \mu \mathrm{g} / \mathrm{ml}$ & N. D. & 8 \\
E-64 & $5 \mu \mathrm{g} / \mathrm{ml}$ & N. D. & 0 \\
& $20 \mu \mathrm{g} / \mathrm{ml}$ & 32 & 15 \\
Pepstatin A & $10 \mu \mathrm{g} / \mathrm{ml}$ & 0 & 11 \\
Soybean trypsin inhibitor & $100 \mu \mathrm{g} / \mathrm{ml}$ & N. D. & 95 \\
Phenylmethyl-sulfonyl fluoride & $1 \mathrm{mM}$ & 100 & 100 \\
Monoiodoacetic & $0.01 \mathrm{mM}$ & 100 & 100 \\
acid & $0.1 \mathrm{mM}$ & 90 & 70 \\
Trifluoperazine & $0.1 \mathrm{mM}$ & 26 & 56 \\
& & N. D. & 100 \\
\hline
\end{tabular}

N. D.: not determined.

Remaining activities in the presence of inhibitors listed above were expressed as a percent of control using casein as the substrate. Each inhibitor was preincubated at $37^{\circ} \mathrm{C}$ for $10 \mathrm{~min}$ without adding calcium in the assay medium.

sured at the indicated $\mathrm{Ca}^{2+}$ concentrations (Fig. 4). There was an enhancement of $\mathrm{Ca}^{2+}$ sensitivity of peak II. Fifty percent activation by $\mathrm{Ca}^{2+}$ was observed at $10^{-7} \mathrm{M}$. During the preincubation and the succeeding dialysis, $83 \%$ of the calpain activity was lost.

Effects of various protease inhibitors on calpain activities

Table 1 shows the effects of various inhibitors on peak I and peak II. Leupeptin and E-64 were the most potent inhibitors used. E-64, one of the synthetic thiol protease inhibitors, is known to be as potent as leupeptin (Handa et al., 1978). Concentrations of leupeptin and E-64 for 50\% inhibition of peak II were $0.5 \mu \mathrm{g} / \mathrm{ml}$ and $2.0 \mu \mathrm{g} / \mathrm{ml}$, respectively. Monoiodoacetic acid suppressed the peak II activity by $44 \%$ at $0.1 \mathrm{mM}$. Pepstatin A, soybean trypsin inhibitor, penylmethylsulfonyl-fluoride and trifluoperazine were not inhibitory at all. As mentioned above, peak II activity seems to share the same characteristics with the thiol proteases.

\section{Substrate specificity}

Various substrates at a concentration of
$1.4 \mathrm{mg} / \mathrm{ml}$ were tested in addition to casein. Bovine serum albumin, ovalbumin, native hemoglobin and porcine thyroglobulin were used. The magnitude of proteolytic activity attributable to thyroglobulin or other proteins contaminated with peak II was estimated by incubation of peak II with or without $\mathrm{Ca}^{2+}$ in the absence of exogenous substrate. The $\mathrm{Ca}^{2+}$-dependent proteolysis in the absence of exogenous substrate was subtracted from the value of $\mathrm{Ca}^{2+}$-dependent proteolysis obtained with each exogenous substrate. The value thus obtained for casein was defined as $100 \%$. Casein was the best substrate, followed in succession by ovalbumin $(52 \%)$, porcine thyroglobulin $(37 \%)$, bovine serum albumin $(14 \%)$ and native hemoglobin $(0 \%)$.

\section{Thyroglobulin proteolysis by peak II}

All the fractions eluted from DEAEcellulose column were tested as the substrate of peak II with the immunoblotting technique. When the F-1 and F-2 were incubated with peak II, thyroglobulin immunoreactivities were detected at mol wt in the 67,000 and 46,000 bands (Fig. 5; F-1, F-2), respectively. Thus, the $67 \mathrm{~K}$ and $46 \mathrm{~K}$ proteins were confirmed to be the products 


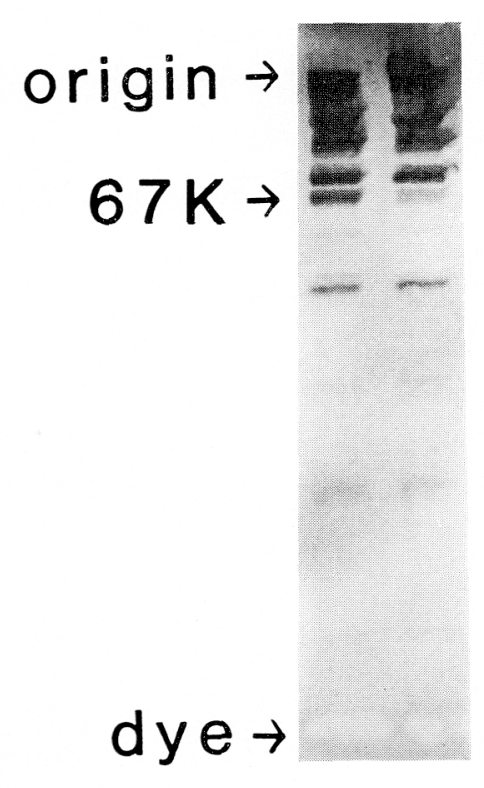

\section{$\mathrm{Ca}$}

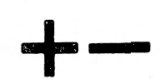

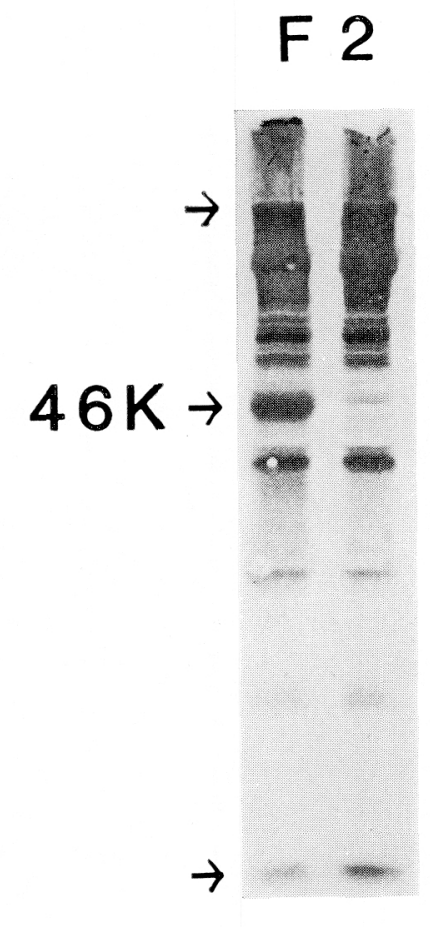

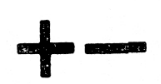

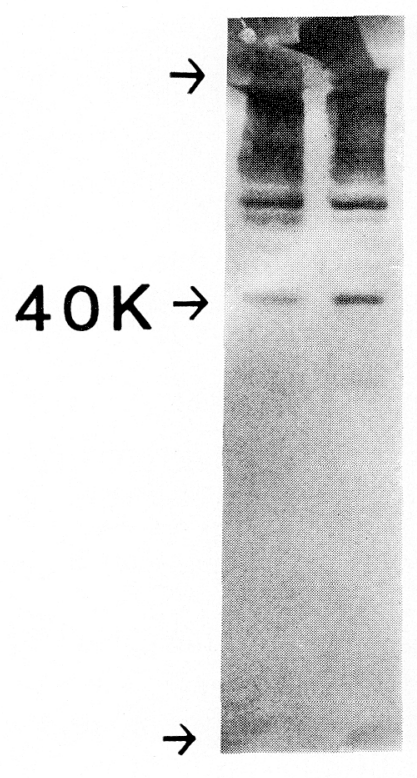

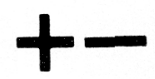

Fig. 5. Immunoblotting of thyroglobulin treated with calpain 2. F-1, F-2, and F-3 treated with calpain 2 were subjected to SDS-polyacrylamide gel electrophoresis and transferred to nitrocellulose membrane. Thyroglobulin-immunoreactivity was detected by using anti-porcine thyroglobulin antiserum $(1: 400)$.

of thyroglobulin proteolysis by calpain 2 . These products were not clearly seen in the absence of $\mathrm{Ca}^{2+}$ in the medium.

When the F-3 was incubated with calpain 2 , thyroglobulin immunoreactive $40 \mathrm{~K}$ protein decreased in the presence of calcium, indicating that $40 \mathrm{~K}$ protein was also the substrate for calpain 2 .

\section{Discussion}

Among the cytosolic proteases, calpains are of interest since many physiological events induced by TSH are linked to $\mathrm{Ca}^{2+}$ in the thyroid gland (Zor et al., 1968; Hashizume et al., 1984). Two $\mathrm{Ca}^{2+}$-depen- dent proteases are separated from each other on DEAE-cellulose column chromatography of hog thyroid cytosol. Peak I showed high $\mathrm{Ca}^{2+}$ sensitivity and peak II had low $\mathrm{Ca}^{2+}$ sensitivity. Peak II digested casein in the neutral $\mathrm{pH}$ range. Peak II was sensitive to thiol protease inhibitors and monoiodoacetic acid, and was insensitive to a calmodulin inhibitor and serine protease inhibitors. This protease is classified in thiol protease and metal-activated protease. All the characteristics described above indicate that peak I and peak II resemble calpain 1 and calpain 2, respectively (Mollgrem, 1980; DeMartino, 1981).

In porcine thyroid, a few proteases in lysosomes have been known to be inhibited 
by thiol protease inhibitors (Nakagawa et al., 1981; Nakagawa and Ohtaki, 1984). They are thought to be cathepsin B and cathepsin $\mathrm{H}$ reported in other tissues (Tawatari et al., 1978). Although they have some characteristics in common with calpains, calpains are different from them in their $\mathrm{Ca}^{2+}$ sensitivity and existence in cytosol.

Alteration of $\mathrm{Ca}^{2+}$ sensitivity from a low sensitive form with a millimolar range of Ka to a highly sensitive form with a micromolar range of $\mathrm{Ka}$ was induced by preincubation with $\mathrm{Ca}^{2+}$. The possibility that the enhancement of $\mathrm{Ca}^{2+}$ sensitivity (Fig. 4) with partial inactivation (Fig. 3) was elicited by the autolysis of calpain itself might be considered. Such great enhancement of the sensitivity of calpain to $\mathrm{Ca}^{2+}$ was also observed in chicken skeletal muscle (Suzuki et al., 1981). This suggests that once the local concentration of $\mathrm{Ca}^{2+}$ in the cytosol is raised to the $\mathrm{mM}$ range, the enhancement of $\mathrm{Ca}^{2+}$ sensitivity may occur. Localization studies have demonstrated that plasma membrane, nucleus, and mitochondria are possible candidates for $\mathrm{Ca}^{2+}$ storage (Popescu et al., 1974 ; Debbas et al., 1975). Although TSH has been shown to increase the intracellular free $\mathrm{Ca}^{2+}$ in thyroid cells (Chorda et al., 1985), it is not clear whether $\mathrm{Ca}^{2+}$ ion increases to the $\mathrm{mM}$ order concentration. The highly $\mathrm{Ca}^{2+}$-sensitive form may be able to work at a physiological $\mathrm{Ca}^{2+}$ concentration. The small activity observed in peak I can be attributed to coelution of the endogenous inhibitor. It is also likely that the activity of peak I is better expressed in intact cells. Whether these highly sensitive forms of peak II and peak I are exactly the same is not clear from the data at hand.

The observation that thyroglobulin was also hydrolysed by calpain 2 is of interest since it is noted that thyroglobulin is released from the thyroid via the lymphatic circulation to some extent (Daniel et al., 1967), and other investigators have shown that thyroglobulin released in the circulation is
TSH-dependent (Unger et al., 1980) and poorly iodinated (Ikekubo et al., 1981). Kohn et al. (1985) demonstrated the existence of a thyroglobulin secretion path which bypasses the Golgi without lysosomal degradation using the rat clonal thyroidal cells (FRTL-5). This may imply that thyroglobulin can be released by passing the normal site of iodination and lysosomal proteolytic degradation as well. Our data further suggest that thyroglobulin is a candidate for an endogenous substrate of calpain 2 in hog thyroid cytosol. Futhermore, it appears to be possible that intra-thyroidal $\mathrm{Ca}^{2+}$-dependent proteolysis is, at least in part, controlled by cytosolic distribution of calpains, its inactivation by $\mathrm{Ca}^{2+}$ and the enhancement of $\mathrm{Ca}^{2+}$ sensitivity.

\section{References}

Corda D., C. Marcocci, L. D. Kohn, J. Axelrord and A. Luini (1985). Association of the changes in cytosolic $\mathrm{Ca}^{2+}$ and iodine efflux induced by thyrotropin and by stimulation of $\alpha 1$-adrenergic receptors in cultured rat thyroid cells. J. Biol. Chem. 260, 9230-9236.

Daniel, P. M., O. E. Pratt, I. M. Roitt and G. Torrigiani (1967). The release of thyroglobulin from the thyroid gland into thyroid lymphatics: The identification of thyroglobulin in the thyroid lymph and in the blood of monkey by physical and immunological methods and its estimation by radioimmunoassay. Immuno$\log y$ 12, 489-504.

Debbas, G., L. Hoffman, E. J. Londong and L. Hurwits (1975). Electron microscopic localization of calcium in vascular smooth muscle. Anal. Res. 182, 447-472.

DeMartino, G. N. (1981). Calcium-dependent proteolytic activity in rat liver: Identification of two proteases with different calcium requirement. Arch. Biochem. Biophys. 211, 253-257.

Fox, J. E. B., C. C. Reynold and D. R. Phillips (1983). Calcium-dependent proteolysis occurs during platelet aggregation. J. Biol. Chem. 258, 9973-9981.

Handa, K., M. Tamai, M. Yamagishi, S. Ohmura, J. Sawada and I. Tanaka (1978). Isolation and characterization of E-64, a new thiol 
protease inhibitor. Agric. Biol. Chem. 42, 523528.

Hashizume, K., K. Ichikawa, I. Komiya and T. Onaya (1984). Thyrotropin-induced calcium efflux from mouse thyroid: Evidence for inhibition by excess iodide. Endocrinology 115, 1672-1677.

Ikekubo, K., M. Kishihara, J. Sanders, J. Jutton and A. B. Schneider (1981). Differences between circulating and tissue thyroglobulin in rats. Endocrinology 109, 427-432.

Inomata, M., M. Hayashi, M. Nakamura, K. Imahori and S. Kawashima (1983). Purification and characterization of a calcium-activated neutral protease from rabbit skeletal muscle which requires calcium ion of $\mu \mathrm{M}$ order concentration. J. Biochem. 93, 291-294.

Kohn, L. D., M. De Luca, P. Santisteban, S. Shifrin, H. Yoh, S. Formisano and E. Consiglio (1985). Thyroglobulin interaction with thyroid membranes; Implication for the regulation of thyroid hormone formation. In: Thyroglobulin the Prothyroid Hormone (Eggo, M. C. and G. N. Burrow eds.), Raven Press, New York pp. 171-190.

Laemmli, U. K. (1970). Cleavage of structural proteins during the assembly of the head of bacteriophage T4. Nature 227, 680-685.

Lowry, O. H., N. J. Rosenbrough, A. L. Farr and R. J. Randa (1951). Protein measurement with the Folin phenol reagent. J. Biol. Chem. 193, 264-275.

Meyer, W. L., E. H. Fisher and E. G. Krebs (1964). Activation of skeletal muscle phosphorylase $\mathrm{b}$ kinase by $\mathrm{Ca}^{++}$. Biochemistry. 3, 1033-1039.

Mollgrem, R. L. (1980). Canine cardiac calciumdependent proteases. Resolution of two forms with different requirement for calcium. FEBS letter 109, 129-133.

Nakagawa, H., Y. Endo and S. Ohtaki (1981). A new protease in hog thyroid lysosomes: A partial purification and characterization of leupeptin sensitive protease. Acta Endocrinol. 98, 390-395.

Nakagawa, H. and S. Ohtaki (1984). Partial purification and characterization of two thiol proteases from hog thyroid lysosomes. Endocrinology 115, 33-40.

Nishiura, I., K. Tanaka, S. Yamamoto and T. Murachi (1978). The occurrence of an inhibitor of $\mathrm{Ca}^{++}$-dependent neutral protease in rat brain. Biochem. 84, 1657-1659.

Pershadsign, J. A. and J. M. McDonald (1980). A high affinity calcium-stimulated magnesiumdependent adenosine triphosphatase in rat adipocytes plasma membrane. J. Biol. Chem. 255, 4087-4093.

Popescu, L. M., I. Diculescu, V. Zele and N. Ionescu (1974). Ultrastructural distribution of calcium in smooth muscle cells of guinea-pig Taenia coli. Cell Tissue Res. 154, 357-378.

Reddy, M. K., J. D. Etlinger, M. Rabiowitz, D. A. Fischman and R. Zak (1975). Removal of $Z$-lines and $\alpha$-actinin from isolated myofibrils by a calcium-activated neutral protease. $J$. Biol. Chem. 250, 4278-4284.

Suzuki, K., S. Tsuji, S. Ishiura, Y. Kimura, S. Kubota and K. Imahori (1981). Autolysis of calcium activated neutral protease of chicken skeletal muscle. J. Biochem. 90, 1987-1998.

Tawatari, T., K. Tanaka, D. Yoshikawa and K. Katsunuma (1978). Purification and properties of a new cathepsin from rat liver. J. Biol. Chem. 84, 659-671.

Towbin, H., T. Staehelin and J. Gordon (1979). Electrophoretic transfer of protein from polyacrylamide gels to nitrocellulose sheets: procedure and some applications. Proc. Natl. Acad. Sci. USA. 76, 4350-4354.

Unger, J., V. B. Heuverswyn, C. Decoster, F. Cantrine, J. Mokel and V. A. Herle (1980). Thyroglobulin and thyroid hormone release after intravenous administration of bovine thyrotropin in man. J. Clin. Endocrinol. Metab. 51, 590-594.

Zor, U., I. P. Lowe, G. Bloom and J. B. Field (1968). The role of calcium $\left(\mathrm{Ca}^{++}\right)$in TSH and dibutyryl 3', 5'-cyclic AMP stimulation of thyroid glucose oxidation and phospholipid synthesis. Biochem. Biophys. Res. Commun. 33, 649-658. 